\title{
Enhancing Egg Quality by Dietary Vitamin E and Selenium Supplementation
}

\section{Vincenzo Tufarelli*}

Department of Emergency and Organ Transplantation (DETO), Section of Veterinary Science and Animal Production, University of Study of Bari 'Aldo Moro', Italy

*Corresponding author: Vincenzo Tufarelli, Department of Emergency and Organ Transplantation (DETO), Section of Veterinary Science and Animal Production, University of Study of Bari 'Aldo Moro', Italy, Tel: 39-080-467-9811; E-mail: vincenzo.tufarelli@uniba.it

Rec date: July 30, 2014, Acc date: July 31, 2014, Pub date: Aug 07, 2014

Copyright: () 2014 Tufarelli V. This is an open-access article distributed under the terms of the Creative Commons Attribution License, which permits unrestricted use, distribution, and reproduction in any medium, provided the original author and source are credited.

Citation: Tufarelli V (2014) Enhancing Egg Quality by Dietary Vitamin E and Selenium Supplementation.Vitam Miner 3: e131. doi:10.4172/vms.1000e131

\section{Editorial}

Vitamin E and selenium (Se) are key components of the antioxidant system, reducing lipid peroxidation [1-2]. Vitamin E is a natural lipidsoluble antioxidant, which, when incorporated into poultry diets, tends to bring about the eggs oxidative stability [3]. Further, vitamin $\mathrm{E}$ is the most active natural antioxidant used in animal diets exhibiting an antioxidant activity at low concentration and prooxidant activity at high concentration [4]. It was reported that dietary a-tocopherol increases the content of vitamin $\mathrm{E}$ in the egg yolk in a dose-dependent manner [1]. It was found that hens supplemented with dietary atocopherol had a significant reduction in thiobarbituric acid reactive substances values, as an indicator of lipid peroxidation in eggs. It was indicated that an increased vitamin E supplementation of the maternal diet can substantially increase vitamin $\mathrm{E}$ concentration in the developing tissues of the chick and significantly decreased their susceptibility to lipid peroxidation [5-6]. Selenium is an essential part of a variety of selenoproteins, the best known of which is Glutathione Peroxidase (GSH-Px). In particular, GSHPx is involved in cellular antioxidant protection, and it has been suggested that GSH-Px works in synergy with vitamin E, because GSH-Px continues the work of vitamin $\mathrm{E}$ by detoxifying hydroperoxides [2]. Selenium can be added to the diet as selenite or selenate (inorganic) and as organic selenium compounds (selenoamino acids, mainly selenomethionine). Organic Se supplements have been reported to increase egg Se more than inorganic Se [2]. In addition, it was shown that addition of organic Se to laying hens' diets can improve the quality of stored eggs [7]. Storage of hens' eggs is a common practice in modern commercial poultry production. However, storage can alter some characteristics of the egg, including loss of water and carbon dioxide, and a subsequent increase in the $\mathrm{pH}$ of the albumen [8]. Furthermore, eggs contain a high proportion of polyunsaturated fatty acids, mainly linoleic acid (C18:2n-6), making them very susceptible to peroxidation and thus increasing the requirement for antioxidants. The egg nutrients are an important characteristic of the diet. It is possible to improve the vitamin $\mathrm{E}$ and Se levels in eggs by manipulating the rations of laying hens [9]. The effect of dietary a-tocopheryl acetate supplementation on enhancing lipid stability in egg-yolk has been already reported [9]. On the other hand, the effect of a-tocopheryl acetate supplementation on the fatty acid composition of eggs has been studied less $[1,9]$.

Because of the key-role of vitamin $\mathrm{E}$ and Se, the choice of improving Se reception in both humans and animals are investigated. Apart from direct vitamin $\mathrm{E}$ and Se supplementation, attention has also been devoted to the option of increasing the nutrition value of food and feed by increasing the inclusion rate of trace elements. However, questions still remain on the benefit as well as the optimum dietary inclusion level of vitamin $\mathrm{E}$ and Se supplementation in laying hens on egg quality.

\section{References}

1. Meluzzi A, Sirri F, Manfreda G, Tallarico N, Franchini A (2000) Effects of dietary vitamin $\mathrm{E}$ on the quality of table eggs enriched with $\mathrm{n}-3$ long-chain fatty acids. Poult Sci 79: 539-545.

2. Surai PF (2002) Selenium in poultry nutrition: 1. Antioxidant properties, deficiency and toxicity. Worlds Poult Sci J 58: 333- 347.

3. Cherian G, Wolfe FW, Sim JS (1996) Feeding dietary oils with tocopherols: Effects on internal qualities of eggs during storage. J Food Sci 61: 15-18.

4. Bölükbasi SC, Erhan MK, Keles MS, Koçyigit R (2007) Effect of dietary vitamin $\mathrm{E}$ on the performance, plasma and egg yolk vitamin $\mathrm{E}$ levels and lipid oxidation of egg in heat stressed layers. J Appl Biol Sci 3: 19-23.

5. Khan RU, Naz S, Nikousefat Z, Tufarelli, Javdani M, e tal. (2011) Effect of vitamin E in heat-stressed poultry. Worlds Poult Sci J 67: 469-478.

6. Khan RU, Rahman ZU, Nikosefat Z, Javdani M, Tufarelli V, et al. (2012) Immunomodulating effects of vitamin E in broilers. Worlds Poult Sci J 68: 31-39.

7. Wakebe M (1998) Organic selenium and egg freshness. Patent \#10-23864. Feed for meat chickens and feed for laying hens. Japanese Patent Office, Application Heisei 8-179629.

8. Decuypere E, Tona K, Bruggeman V, Bamelis F (2001) The day-old chick: A crucial hinge between breeders and broilers. Worlds Poult Sci J 57: 127 139.

9. Mohiti-Asli M, Shariatmadari F, Lotfollahian H, Mazuji MT (2008) Effects of supplementing layer hen diets with selenium and vitamin E on egg quality, lipid oxidation and fatty acid composition during storage. Can J Anim Sci 88: 475-483. 